\title{
Photodynamic therapy-triggered on-demand drug release from ROS- responsive core-cross-linked micelles toward synergistic anti-cancer treatment
}

\author{
Yongjuan $\mathrm{Li}^{1}$, Jian $\mathrm{Hu}^{2}$, Xun Liu${ }^{1}$, Yong Liư ${ }^{3}(\varangle)$, Shixian Lv ${ }^{1}$, Juanjuan Dang ${ }^{1}$, Yong $\mathrm{Ji}^{4}(\varangle)$, Jinlin $\mathrm{He}^{2}$, and Lichen Yin ${ }^{1}$ \\ ${ }^{1}$ Institute of Functional Nano and Soft Materials (FUNSOM), Jiangsu Key Laboratory for Carbon-Based Functional Materials and Devices, Soochow \\ University, Suzhou 215123, China \\ ${ }^{2}$ College of Chemistry, Chemical Engineering and Materials Science, Suzhou Key Laboratory of Macromolecular Design and Precision Synthesis, Jiangsu Key \\ Laboratory of Advanced Functional Polymer Design and Application, Soochow University, Suzhou 215123, China \\ ${ }^{3}$ Department of Biomedical Engineering, University of Groningen and University Medical Center Groningen, Antonius Deusinglaan 1, 9713 AV Groningen, \\ The Netherlands \\ ${ }^{4}$ Department of Cardiothoracic Surgery, Wuxi People's Hospital Affiliated to Nanjing Medical University, Wuxi 214023, China
}

(C) The Author(s) 2019

Received: 16 December 2018/ Revised: 3 February 2019 / Accepted: 4 February 2019

\begin{abstract}
Polymeric micelles have demonstrated wide utility for chemodrug delivery, which however, still suffer from shortcomings such as undesired drug loading, disassembly upon dilution, pre-leakage of drug cargoes during systemic circulation, and lack of cancer-selective drug release. Herein, a poly(ethylene glycol) (PEG)-polyphosphoester-based, reactive oxygen species (ROS)-responsive, core-cross-linked (CCL) micellar system was developed to encapsulate both chemodrug (doxorubicin, Dox) and photosensitizer (chlorin e6, Ce6). The hydrophobic core of the micelles was cross-linked via a thioketal (TK)-containing linker, which notably enhanced the drug loading and micelle stability. In tumor cells, far-red light irradiation of Ce6 generated ROS to cleave the TK linkers and disrupt the micelle cores. As such, micelles were destabilized and Dox release was promoted, which thereafter imparted synergistic anti-cancer effect with ROS-mediated photodynamic therapy. This study provides an effective approach to realize the precise control over drug loading, formulation stability, and cancer-selective drug release using polymeric micelles, and would render promising utilities for the programmed anti-cancer combination therapy.
\end{abstract}

\section{KEYWORDS}

core-cross-linked micelles, on-demand drug release, photodynamic therapy, reactive oxygen species (ROS) responsiveness, synergistic anti-cancer therapy

\section{Introduction}

Polymeric micelles (PMs) have been extensively used for anticancer therapeutic delivery, owing to their desired capabilities to enhance the solubility of drugs, prolong blood circulation, improve tumor accumulation through the enhanced permeability and retention (EPR) effect, and reduce side effects [1-5]. Nevertheless, clinical applications of PMs are largely limited by the premature disintegration before they reach the tumor sites [6-8]. Additionally, most of the therapeutics are loaded in PMs via weak hydrophobic interactions, and increasing evidence has suggested that the thermo-dynamic PMs could disassemble in the blood circulation because of the extensive dilution, and the unexpected drug leakage will occur to cause serious side effects [9-11]. Lam et al. found that when the drug loading of micelles was lower than $5 \mathrm{wt} \%$, polymers inside the micelles were mostly inter-molecularly overlapped [12]. Thereby the micelles possessed suitable and stable sizes to reach the tumor sites through the EPR effect. However, when the drug loading was higher than $5 \mathrm{wt} . \%$, the micelles may re-assemble into bigger micelles with a small portion of drugs ( $<19 \%)$ leaking from the micelles during the re-assembly [13]. Therefore, it is highly demanded to stabilize the micelle systems while maintaining satisfactory drug loading.
To increase the stability of PMs and prevent the immature drug release, the core-cross-linking strategy has been proposed [14-17]. The chemical cross-linking could effectively resist the dilutioninduced micelle disassembly, and the more compact hydrophobic core would afford better drug encapsulation capability. To further enable on-demand drug release in cancer tissues/cells, stimuliresponsive core-cross-linked (CCL) micelles that can undergo selective de-cross-linking upon cancer-specific triggers have been investigated for drug delivery. Commonly utilized stimuli include $\mathrm{pH}[18,19]$, redox [20], reactive oxygen species (ROS) [21, 22], and enzymes [23], etc. However, these triggers often lack cancer selectivity (such as $\mathrm{pH}$ and redox), have heterogeneous intensity among different tumor types, or are not strong enough to provoke pronounced responsiveness from the vehicles. For instance, the ROS concentration in cancer cells is often insufficient to trigger the transformation of ROS-responsive domains, such as thioketal (TK) [24], arylboronic acid [25], thioether [26], selenium [27, 28], and tellurium [29, 30]. While development of CCL micelles with higher ROS sensitivity would be a promising approach, it is chemically challenging to design new and ultra-ROS-responsive domain. An alternative approach to 
address this issue could be manually elevating the ROS levels in cancer cells $[31,32]$, thus magnifying the response of nanovehicles to ROS.

Photodynamic therapy (PDT), involving the production of various types of ROS by photosensitizers (PSs) under light activation, is regarded as a promising strategy for cancer therapy [33-37]. Compared with surgery and chemotherapy, PDT features less invasiveness, better tumor localization, and minimal drug resistance [38-40]. More importantly, the high levels of ROS generated by PDT can not only induce cancer cell apoptosis and necrosis, but can also create a specific ROS-rich microenvironment to trigger on-demand de-cross-linking of the ROS-responsive CCL micelles to enable selective chemodrug release in cancer cells.

Herein, we report the design of a core-cross-linked, poly(ethylene glycol) (PEG)-polyphosphoester-based micellar system for the co-delivery of chemodrug (doxorubicin, Dox) and photosensitizer (chlorin e6, Ce6). The core of the micelles was stabilized via cross-linking by the TK-containing linkers, and the PEG shell could stabilize the whole micellar system and enable long circulation in the blood. Dox and Ce6 were co-encapsulated into the cross-linked hydrophobic core of the CCL micelles, thus preventing premature leakage during systemic circulation. Upon reaching the tumor tissues, the site-specific far red light irradiation $\left(660 \mathrm{~nm}, 5 \mathrm{~mW} / \mathrm{cm}^{2}\right)$ could generate extensive ROS which can break down the TK cross-linker to destabilize the micelles and trigger instantaneous Dox release. Synergistically, the released Dox and the generated ROS will lead to apoptosis and necrosis of the cancer cells (Scheme 1).

\section{Experimental}

\subsection{Materials, cells, and animals}

Ce6 was purchased from Frontier Scientific (Newark, USA). 3-Mercaptopropionic acid, 2-chloroethylamine hydrochloride, obenzotriazole-N,N,N',N'-tetramethyluronium hexafluorophosphate (HBTU), 1-hydroxybenzotriazole (HOBt), copper(II) sulfate $\left(\mathrm{CuSO}_{4}\right)$, sodium ascorbate, pentamethyldiethylenetriamine (PMDEM), poly(ethylene glycol) methyl ether (PEG-OH) $\left(M_{\mathrm{n}}=5 \mathrm{kDa}\right)$, and sodium azide were purchased from Energy Chemical (Shanghai, China). Dichloromethane (DCM), anhydrous sodium sulfate $\left(\mathrm{Na}_{2} \mathrm{SO}_{4}\right)$, anhydrous tetrahydrofuran (THF), diethyl ether $\left(\mathrm{Et}_{2} \mathrm{O}\right)$, dimethylformamide (DMF), anhydrous acetone, hydrogen peroxide $\left(\mathrm{H}_{2} \mathrm{O}_{2}\right)$, and pyrene were purchased from Sinopharm Chemical Reagent Co., Ltd (Shanghai, China). Dox, deuterated chloroform $\left(\mathrm{CDCl}_{3}\right)$, deuterated water $\left(\mathrm{D}_{2} \mathrm{O}\right)$, deuterated dichlorosulfoxide $\left(\mathrm{DMSO}-\mathrm{d}_{6}\right)$, and stannous octoate $\left(\mathrm{Sn}(\mathrm{Oct})_{2}\right)$ were purchased from J\&K (Shanghai, China). All chemicals were used as received unless otherwise indicated. 2-(But-3-yn-1-yloxy)-2-oxo-1,3,2dioxaphospholane (BYP) was synthesized as reported before [41]. 3-(4,5-Dimethylthiahiazol-2-yl)-2,5-diphenyl-2H-tetrazolium bromide (MTT) was purchased from Invitrogen (Carlsbad, CA, USA).

4T1 (mouse mammary carcinoma) and MCF-7 (human breast adenocarcinoma) cells were purchased from the American Type Culture Collection (Rockville, MD, USA). MCF-7 cells were cultured in Dulbecco's modified Eagle medium (DMEM) (Gibco, Grand Island, NY, USA) containing 10\% fetal bovine serum (FBS). 4T1

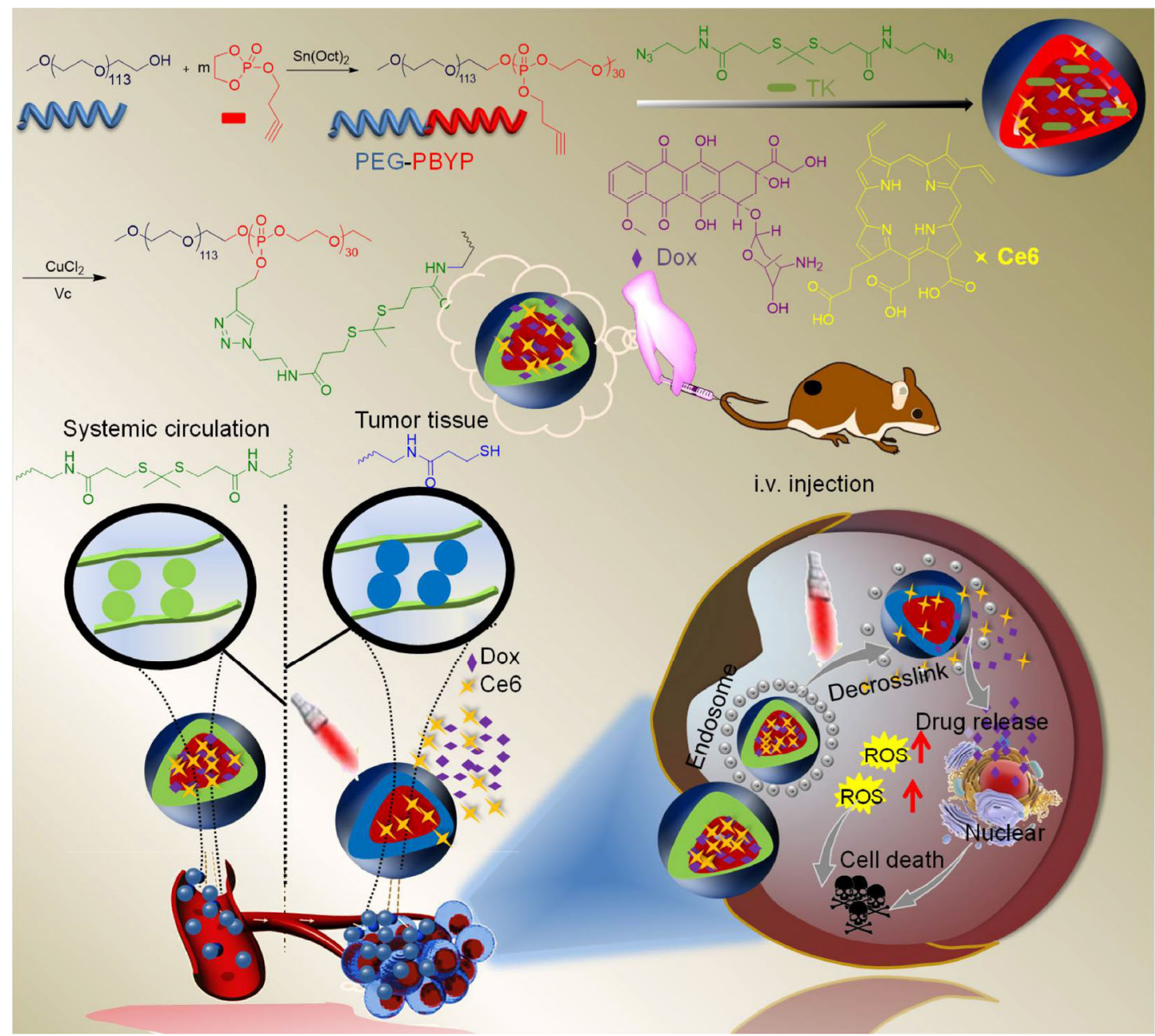

Scheme 1 Illustration of ROS-sensitive core-cross-linked PEG-PBYP micelles for synergistic cancer therapy. When the micelles reached the tumor areas through EPR effect and then entered the cells via endocytosis, the PS was activated to produce numerous of ROS, triggered decrosslinked of the micelles and speeded drug release. 
cells were cultured in 1640 medium (Gibco, Grand Island, NY, USA) containing $10 \%$ FBS.

Female BALB/c mice (6-8 week, 18-20 g) were obtained from Shanghai Slaccas Experimental Animal Co., Ltd (Shanghai, China), and were housed in an SPF room. The animal experimental protocols were approved by the Institutional Animal Care and Use Committee, Soochow University.

\subsection{Synthesis and characterization of poly(ethylene glycol)- block-poly(2-(but-3-yn-1-yloxy)-2-oxo-1,3,2-dioxaphospholane) (PEG-PBYP)}

PEG-PBYP was synthesized via ring-opening polymerization (ROP) of BYP as initiated by PEG-OH [42]. Briefly, in a glovebox, BYP (105 mg, $0.6 \mathrm{mmol}), \mathrm{Sn}(\mathrm{Oct})_{2}(8.1 \mathrm{mg}, 0.02 \mathrm{mmol})$, and PEG-OH (100 mg, $0.02 \mathrm{mmol}$ ) were dissolved in anhydrous THF $(5 \mathrm{~mL})$, and the solution was stirred at $40{ }^{\circ} \mathrm{C}$ for $24 \mathrm{~h}$. The final product PEGPBYP was obtained as white powder after precipitation with diethyl ether/methanol $(10: 1, \mathrm{v} / \mathrm{v})$. The copolymer structure was characterized by ${ }^{1} \mathrm{H}$ NMR, and the molecular weight distribution was determined by gel permeation chromatography (GPC) (Table S1 in the Electronic Supplementary Material (ESM)).

\subsection{Synthesis and characterization of the TK-containing cross-linker}

3-Mercaptopropionic acid (5.2 g, $49.1 \mathrm{mmol}$ ) and anhydrous acetone $(5.8 \mathrm{~g}, 98.2 \mathrm{mmol})$ were mixed in a flask under a dry $\mathrm{HCl}$ atmosphere at room temperature. After $6 \mathrm{~h}$, the mixture was crystallized in an ice-salt bath. The crude product was successively washed with hexane $(3 \times 50 \mathrm{~mL})$ and cold water $(3 \times 50 \mathrm{~mL})$, and 3,3'-(propane-2,2-diylbis(sulfanediyl))dipropionic acid (compound 1) was obtained as white solid (5.5 g, yield 65.2\%) [43].

Sodium azide (5.85 g, $90 \mathrm{mmol}$ ) and 2-chloroethylamine hydrochloride $(5.22 \mathrm{~g}, 45 \mathrm{mmol})$ were dissolved in water $(50 \mathrm{~mL})$, and the mixture was stirred at $80{ }^{\circ} \mathrm{C}$ for $24 \mathrm{~h}$. After the $\mathrm{pH}$ was adjusted to 12 using $\mathrm{NaOH}$ solution $(1 \mathrm{~mol} / \mathrm{L})$, the reaction mixture was extracted with $\mathrm{Et}_{2} \mathrm{O}(3 \times 50 \mathrm{~mL})$. The organic phase was combined and dried over anhydrous $\mathrm{Na}_{2} \mathrm{SO}_{4}$. The mixture was filtered and the solvent was removed by vacuum. To avoid explosion, a small portion of solvent must be left. 3-Azidoethan-1-amine (compound 2) (7.5 g, yield $66.7 \%$ ) was obtained as colorless oil [44].

Compound 1 (1.05 g, $1 \mathrm{mmol})$ and compound $2(8.04 \mathrm{~g}, 2 \mathrm{mmol})$ were dissolved in dry DMF (30 mL). HBTU (606 mg, $1.6 \mathrm{mmol}, 1.6$ eq.) and HOBt (216 mg, $1.6 \mathrm{mmol}, 1.6$ eq.) dissolved in DMF (10 mL) were added. After stirring at room temperature for $24 \mathrm{~h}$, the reaction mixture was extracted with $\mathrm{Et}_{2} \mathrm{O}(3 \times 100 \mathrm{~mL})$. The organic phase was combined and dried over anhydrous $\mathrm{Na}_{2} \mathrm{SO}_{4}$ before the solvent was removed by vacuum. The crude product was purified by flash silica gel column chromatography with DCM/hexane $(1 / 1, \mathrm{v} / \mathrm{v})$ as the eluent, and the TK-containing cross-linker (compound 3) was obtained as yellow powder [45].

The non-responsive cross-linker, 1,6-diazidohexane (compound 4), was synthesized using a similar method as described before [46].

\subsection{Preparation and characterization of micelles}

The ROS-responsive core-cross-linked (RCCL) micelles, nonresponsive core-cross-linked (NCCL) micelles, and un-cross-linked (UCL) micelles were prepared via the nanoprecipitation method (Table 1). Taking RCCL micelles as an example, PEG-PBYP ( $10 \mathrm{mg} / \mathrm{mL}$ in DMF, $100 \mu \mathrm{L}, 1$ eq. of alkyne groups) and compound $3(10 \mathrm{mg} / \mathrm{mL}$ in DMF, $50 \mu \mathrm{L})$ were mixed together, which was added dropwisely into deionized water $(2 \mathrm{~mL})$ under vigorous stirring. After $1 \mathrm{~h}, \mathrm{CuSO}_{4}\left(4.1 \times 10^{-3} \mathrm{mmol}, 0.25 \mathrm{~mol}\right.$ eq. of the alkynyl groups), sodium ascorbate $\left(4.1 \times 10^{-3} \mathrm{mmol}, 0.25 \mathrm{~mol}\right.$ eq. of the alkynyl groups) and PMDEM $\left(4.1 \times 10^{-3} \mu \mathrm{mol}, 0.025 \mu \mathrm{mol}\right.$ eq. of the alkynyl groups $)$ were added under the nitrogen atmosphere. After stirring for $24 \mathrm{~h}$, the RCCL micelles were obtained followed by dialysis against deionized water for $24 \mathrm{~h}(\mathrm{MWCO}=3.5 \mathrm{kDa})$. The micelles were characterized by dynamic laser scattering (DLS) and transmission electron microscopy (TEM). Compound 4 instead of compound 3 was used to prepare the NCCL micelles using the same method. For UCL micelles, PEG-PBYP was nanoprecipitated into deionized water in the absence of the crosslinker using the similar method.

Pyrene was used as the probe to determine the critical micelle concentration (CMC) of the polymers [47]. Pyrene dissolved in acetone $(0.6 \mathrm{mM}, 1 \mathrm{~mL})$ was put in the vial, and acetone was removed via volatilization. Then UCL micelles with different concentrations varied from $6.0 \times 10^{-4}$ to $0.15 \mathrm{mM}$ were added to the vials under stirring. The fluorescence intensity of the solution was recorded using a fluorescence spectrometer with the excitation wavelength of 290-360 $\mathrm{nm}$ and the emission wavelength of $390 \mathrm{~nm}$. The crosspoint of the intensity ratio $I_{372} / I_{383}$ at the lowest and the highest concentration was the CMC of micelles.

\subsection{Stability and ROS-triggered de-crosslinking of RCCL micelles}

Sizes of the RCCL, NCCL, and UCL micelles ( $1 \mathrm{mg} / \mathrm{mL}$ in water) after dilution with DMF for 10 fold were determined by DLS. To probe the ROS-sensitivity, RCCL, NCCL, and UCL micelles $(1 \mathrm{mg} / \mathrm{mL}$ in water) were treated with $\mathrm{H}_{2} \mathrm{O}_{2}(0.5 \mathrm{mM})$ for $4 \mathrm{~h}$. Changes of the size and morphology were explored by DLS and TEM. The CMC of the TK-crosslinked PEG-PBYP after treatment with $\mathrm{H}_{2} \mathrm{O}_{2}(0.5 \mathrm{mM}, 4 \mathrm{~h})$ was also determined with the same method as described above.

\subsection{Drug encapsulation and ROS-responsive drug release}

The drug-loaded micelles were prepared using the same method as described for the blank micelles, except that the drug cargoes were mixed with the polymer and crosslinker before being nanoprecipitated into water. For example, in order to prepare Dox and Ce6-co-loaded RCCL micelles (RCCL-DC), PEG-PBYP $(10 \mathrm{mg} / \mathrm{mL}$ in DMF, $100 \mu \mathrm{L}$, 1 eq. of the alkyne groups), compound $3(10 \mathrm{mg} / \mathrm{mL}$ in DMF, $50 \mu \mathrm{L})$, Dox $(5 \mathrm{mg} / \mathrm{mL}$ in DMF, $60 \mu \mathrm{L})$, and Ce6 $(5 \mathrm{mg} / \mathrm{mL}$ in DMF, $60 \mu \mathrm{L})$ were mixed together and the solution was added dropwisely into deionized water $(3 \mathrm{~mL})$ (theoretical drug loading of both Dox and Ce6 at $23.1 \%)$ under vigorous stirring. After $1 \mathrm{~h}, \mathrm{CuSO}_{4}\left(4.1 \times 10^{-3} \mathrm{mmol}\right.$, 0.25 eq. of the alkyne groups), sodium ascorbate $\left(4.1 \times 10^{-3} \mathrm{mmol}\right.$, 0.25 eq. of the alkyne groups), and PMDEM $\left(4.1 \times 10^{-3} \mu \mathrm{mol}, 0.025\right.$ eq. of the alkyne groups) were added into the solution under nitrogen atmosphere. After $24 \mathrm{~h}$, the micelles were obtained and dialyzed against deionized water for $24 \mathrm{~h}(\mathrm{MWCO}=3.5 \mathrm{kDa})$. The whole process was kept in the dark.

The Dox-loaded RCCL micelles (RCCL-Dox), Ce6-loaded RCCL micelles (RCCL-Ce6), and 1,1-dioctadecyl-3,3,3,3-tetramethylindotricarbocyanine iodide (DiR)-loaded RCCL micelles (RCCL-DiR) were prepared similarly. The Dox-loaded NCCL micelles (NCCLDox), Ce6-loaded NCCL micelles (NCCL-Ce6), and Dox- and Ce6-co-loaded NCCL micelles (NCCL-DC) were prepared similarly expect that the TK-containing cross-linker was replaced by the non-responsive cross-linker (compound 4).

The Dox- and Ce6-co-loaded un-cross-linked micelles (UCL-DC) were prepared as follows. PEG-PBYP $(10 \mathrm{mg} / \mathrm{mL}$ in DMF, $100 \mu \mathrm{L})$, Dox $(5 \mathrm{mg} / \mathrm{mL}$ in DMF, $60 \mu \mathrm{L})$, and Ce6 $(5 \mathrm{mg} / \mathrm{mL}$ in DMF, $60 \mu \mathrm{L})$ were mixed together and the solution was added dropwisely into deionized water $(3 \mathrm{~mL})$ under vigorous stirring. After $4 \mathrm{~h}$, the micelles were obtained and dialyzed against deionized water for $24 \mathrm{~h}$ (MWCO = $3.5 \mathrm{kDa}$ ). The whole process was kept in the dark. The DiR-loaded UCL micelles (UCL-DiR) were prepared using the same process.

To determine the drug loading in the micelles, RCCL-DC micelles ( $1 \mathrm{~mL}$ ) were incubated with $\mathrm{H}_{2} \mathrm{O}_{2}(0.5 \mathrm{mM})$ for $4 \mathrm{~h}$. Then, the mixture was taken $(10 \mu \mathrm{L})$, mixed with DMF $(990 \mu \mathrm{L})$, and kept in 
the dark for $24 \mathrm{~h}$. The content of Dox and Ce6 in the solution was determined by spectrofluorimetry (Dox: $\lambda_{\mathrm{ex}}=485 \mathrm{~nm}, \lambda_{\mathrm{em}}=592$ $\mathrm{nm}$, Ce6: $\left.\lambda_{\mathrm{ex}}=630 \mathrm{~nm}, \lambda_{\mathrm{em}}=666 \mathrm{~nm}\right)$. Drug loading capacity (DLC) and drug loading efficiency (DLE) were calculated according to the following formulas

DLC $(\%)=$ (weight of loaded drug/total weight of polymer and loaded drug) $\times 100 \%$

DLE $(\%)=($ weight of loaded drug/weight of feeding drug $) \times 100 \%$

To explore the ROS-responsive Dox release profiles, RCCL-Dox micelles $(25 \mu \mathrm{g}$ Dox $/ \mathrm{mL}$ and $12.4 \mu \mathrm{g} \mathrm{Ce} / \mathrm{mL}, 1 \mathrm{~mL})$ were placed in a dialysis bag $(\mathrm{MWCO}=3.5 \mathrm{kDa})$ which was immersed in phosphate buffer saline (PBS) $(7.4,25 \mathrm{~mL})$ containing $\mathrm{H}_{2} \mathrm{O}_{2}$ at various concentrations $(0,0.1$, and $0.5 \mathrm{mM})$ and incubated at $37^{\circ} \mathrm{C}$ under shaking. At determined time intervals, $2 \mathrm{~mL}$ of the release medium was withdrawn and refreshed with the same volume of release medium. The amount of Dox in the harvested release medium was determined by spectrofluorimetry $\left(\lambda_{\mathrm{ex}}=485 \mathrm{~nm}, \lambda_{\mathrm{em}}=592 \mathrm{~nm}\right)$.

The light-triggered Dox release from RCCL-DC micelles was further explored. RCCL-DC micelles $(25 \mu \mathrm{g}$ Dox $/ \mathrm{mL}$ and $12.4 \mu \mathrm{g}$ $\mathrm{Ce} 6 / \mathrm{mL}, 1 \mathrm{~mL})$ were placed in a dialysis bag $(\mathrm{MWCO}=3.5 \mathrm{kDa})$ and irradiated $\left(660 \mathrm{~nm}, 5 \mathrm{~mW} / \mathrm{cm}^{2}\right)$ for $0.5 \mathrm{~h}$. The dialysis bag was then immersed in PBS $(7.4,25 \mathrm{~mL})$ and incubated at $37{ }^{\circ} \mathrm{C}$ under shaking. The amount of Dox released at pre-determined time intervals was determined as described above.

\subsection{Detection of light-mediated intracellular ROS production}

Light-induced ROS generation in $4 \mathrm{~T} 1$ cells was detected using a ROS probe, 2',7'-dichlorodihydrofluorescein diacetate (DCFH-DA). Cells were seeded in a 24 -well plate at $3 \times 10^{4}$ cells/well and cultured for $24 \mathrm{~h}$. RCCL-Ce6 micelles were added (1 $\mu \mathrm{g}$ Ce6/mL). After incubation for $4 \mathrm{~h}$, the DCFH-DA solution was added $(10 \mu \mathrm{M})$ and incubated with cells for another $20 \mathrm{~min}$. The culture medium was replaced with fresh medium and irradiated $\left(660 \mathrm{~nm}, 5 \mathrm{~mW} / \mathrm{cm}^{2}\right)$ for $0.5 \mathrm{~h}$. Cells were then fixed with paraformaldehyde (4\%), stained with 4',6-diamidino-2-phenylindole (DAPI) $(5 \mu \mathrm{g} / \mathrm{mL})$, and observed by confocal laser scanning microscopy (CLSM).

\subsection{In vitro cellular uptake}

Briefly, 4T1 cells were seeded on 24 -well plates $\left(3 \times 10^{4}\right.$ cells/well $)$ and cultured for $24 \mathrm{~h}$. The medium was replaced with fresh medium, into which UCL-DC, NCCL-DC, or RCCL-DC micelles were added at the final Dox concentration of $1 \mu \mathrm{g} / \mathrm{mL}$ and $\mathrm{Ce} 6$ concentration of $0.5 \mu \mathrm{g} / \mathrm{mL}$. After incubation for 8 or $12 \mathrm{~h}$, cells were fixed with $4 \%$ paraformaldehyde, stained with DAPI $(5 \mu \mathrm{g} / \mathrm{mL})$, and observed by CLSM. Alternatively, cells were treated with UCL-DC, RCCL-DC, and NCCL-DC micelles for $8 \mathrm{~h}$, irradiated $\left(660 \mathrm{~nm}, 5 \mathrm{~mW} / \mathrm{cm}^{2}\right)$ for $0.5 \mathrm{~h}$, and further incubated for $4 \mathrm{~h}$ before CLSM. To quantify the cellular uptake level, cells treated as described above were collected, resuspended in PBS, and subjected to flow cytometry analysis.

\subsection{In vitro antitumor efficacy}

The in vitro antitumor activity of the drug-loaded micelles was evaluated in $4 \mathrm{~T} 1$ and MCF-7 cells. Briefly, cells were seeded in a 96-well plate at $7 \times 10^{3}$ cells/well and incubated for $24 \mathrm{~h}$. The medium was replaced with fresh medium $(90 \mu \mathrm{L})$, into which various micelles (RCCL-Dox, RCCL-Ce6, RCCL-DC, and NCCL-DC, $10 \mu \mathrm{L}$ ) were added at various final Dox equivalent concentrations. After incubation for $8 \mathrm{~h}$, cells treated with RCCL-DC, RCCL-Ce6, and NCCL-DC micelles were irradiated $\left(660 \mathrm{~nm}, 5 \mathrm{~mW} / \mathrm{cm}^{2}\right)$ for $0.5 \mathrm{~h}$. After incubation for another $48 \mathrm{~h}$, the cell viability was determined using the MTT assay.

A live/dead double-staining assay was adopted to assess the cytotoxicity. $4 \mathrm{~T} 1$ cells were seed on 24 -well plates $\left(3 \times 10^{4}\right.$ cells/well), cultured for $24 \mathrm{~h}$, treated with free Dox or various micelles at $2 \mu \mathrm{g}$
Dox equivalent $/ \mathrm{mL}$ for $8 \mathrm{~h}$, irradiated $\left(660 \mathrm{~nm}, 5 \mathrm{~mW} / \mathrm{cm}^{2}\right)$ for $0.5 \mathrm{~h}$, and further incubated for $48 \mathrm{~h}$. Cells were then stained with calceinacetoxymethyl ester (calcein-AM) $(2 \mu \mathrm{M}$, for live cells) and propidium iodide (PI, $4.5 \mu \mathrm{M}$, for dead cells) for $15 \mathrm{~min}$ before observation by CLSM.

The cell apoptosis induced by drug-loaded micelles was further evaluated. $4 \mathrm{~T} 1$ cells were seed on 6 -well plates $\left(3 \times 10^{6}\right.$ cells/well $)$ and treated with Dox or various micelles as described above. Cells were collected, stained using the Annexin V-FITC/PI kit (Beyotime, Shanghai, China), and subjected to flow cytometry analysis.

\subsection{Pharmacokinetics and biodistribution}

RCCL-DiR micelles, UCL-DiR micelles, or free DiR were i.v. injected to female $\mathrm{BALB} / \mathrm{c}$ mice at $5.0 \mathrm{mg} \mathrm{DiR} / \mathrm{kg}$. At predetermined time points, blood $(50 \mu \mathrm{L})$ was collected from the orbit and mixed with Triton X-100 $(1 \%, 600 \mu \mathrm{L})$. DiR in the blood was extracted with $\mathrm{HCl}$ ( $1 \%$ in isopropyl alcohol, $900 \mu \mathrm{L}$ ), and the DiR content was determined by spectrofluorimetry $\left(\lambda_{\mathrm{ex}}=748 \mathrm{~nm}, \lambda_{\mathrm{em}}=780 \mathrm{~nm}\right)$. The half-life time $\left(t_{1 / 2}\right)$ of the micelles was calculated according to the previously reported method [48].

For the biodistribution study, 4T1 cells $\left(2.5 \times 10^{6}\right)$ were s.c. injected into the right flank of female $\mathrm{BALB} / \mathrm{c}$ mice. When the tumor reached $\sim 200 \mathrm{~mm}^{3}$, RCCL-DiR micelles, UCL-DiR micelles, and free DiR were i.v. injected at $5.0 \mathrm{mg} \mathrm{DiR} / \mathrm{kg}$. Live animal fluorescence imaging was performed at predetermined time intervals $(4,6,12$, and $24 \mathrm{~h}$ post-injection) using a Maestro living imaging system (Cambridge Research and Instrumentation, Inc.). In another parallel study, mice were sacrificed at $12 \mathrm{~h}$ post injection, and the major organs (heart, liver, spleen, lung, and kidney) as well as tumors were collected and imaged. The relative fluorescence intensity of $\mathrm{DiR}$ in each tissue was quantified $\left(\lambda_{\mathrm{ex}}=748 \mathrm{~nm}, \lambda_{\mathrm{em}}=780 \mathrm{~nm}\right)$.

\subsection{In vivo antitumor efficacy}

4T1 xenograft tumor-bearing mice as described above were used to evaluate the in vivo anticancer efficacy of drug-loaded micelles. When the tumor volume reached $50-60 \mathrm{~mm}^{3}$, mice were randomly divided into six groups (eight mice per group), and they were i.v. injected with PBS, free Dox, RCCL-Dox, RCCL-Ce6, RCCL-DC, and UCCLDC micelles on day 1, 4, and 7. The Dox and Ce6 doses for micelles were 10 and $4 \mathrm{mg} / \mathrm{kg}$, respectively, while the dose for free Dox was $5 \mathrm{mg} / \mathrm{kg}$. For RCCL-Ce6, RCCL-DC, and UCCL-DC micelles, the tumor sites were irradiated $\left(660 \mathrm{~nm}, 5 \mathrm{~mW} / \mathrm{cm}^{2}\right)$ for $0.5 \mathrm{~h}$ at $12 \mathrm{~h}$ post injection. The tumor volume and body weight were measured every other day. The tumor volume was calculated according to the following formula: ( $V=$ length $\times$ width $\times$ width/2). Mice with tumors larger than $1,000 \mathrm{~mm}^{3}$ should be euthanized according to the standard animal protocol. Thus, on day 16, mice were sacrificed, and major organs as well as tumors were harvested, fixed with $10 \%$ formalin, embedded in paraffin, and sectioned. The tissue sections were stained with hematoxylin and eosin (H\&E) for histological evaluation. The tumor tissues were also embedded in optimal cutting temperature (OCT) compound, frozen, and cryo-sectioned. The tumor sections were stained using the One Step TUNEL Apoptosis Assay kit (Beyotime Biotechnology) to evaluate tumor cell apoptosis.

\subsection{Statistical analysis}

Statistical analysis was performed using Student's $t$-test. The differences between two groups were determined to be significant at ${ }^{*} p<0.05$ and very significant at ${ }^{* *} p<0.01$ and ${ }^{* *} p<0.001$.

\section{Results and discussion}

\subsection{Synthesis and characterization of PEG-PBYP copolymers}

The PEG-PBYP polymer was synthesized via the ring-opening polymerization of BYP using PEG-OH as the macro-initiator and 
$\mathrm{Sn}(\mathrm{Oct})_{2}$ as the catalyst (Scheme $\mathrm{S} 1$ in the ESM). The polyphosphoester was selected as the backbone owing to its biocompatibility, biodegradability, and amenability for post-functionalization [49]. ${ }^{1} \mathrm{H}$ NMR analysis confirmed the successful synthesis of PEG-PBYP (Fig. S1 in the ESM), and the degree of polymerization (DP) of PBYP was calculated to be 28 by comparing the peak intensities of the methylene protons of PEG $(\delta, 3.70 \mathrm{ppm})$ and the alkynyl protons of BYP $(\delta, 2.5 \mathrm{ppm})$. The molecular weight $(\mathrm{MW})$ and polydispersity index (PDI) of the PEG-PBYP polymer were determined to be $11.3 \mathrm{kDa}$ and 1.20 by GPC, respectively (Table S1 in the ESM). Both the ROSresponsive, TK-containing cross-linker and the non-responsive crosslinker were synthesized accordingly (Scheme S1 in the ESM), and their structures were confirmed by ${ }^{1} \mathrm{H}$ NMR (Figs. S2-S5 in the ESM).

\subsection{Characterization and ROS-sensitivity of the RCCL micelles}

The micelles were prepared using the nanoprecipitation method, and they were chemically cross-linked to form CCL micelles. Sizes of the UCL, RCCL and NCCL micelles were determined to be around $91.5,64.2$, and $63.5 \mathrm{~nm}$ by DLS, respectively, with a narrow distribution (Fig. 1(a)). The reduced diameter of micelles after cross-linking could be attributed to the chemical cross-linking of the hydrophobic segment that rendered the micelle cores more compact. TEM images revealed spherical structures of the micelles, and revealed a more compact core of CCL micelles than the UCL micelles, as evidenced by the darkness in TEM images (Fig. 1(d)). Upon dilution with DMF for 10 fold, UCL micelle showed no DLS signals, indicating complete dissolution and dissociation of the micelles (Fig. 1(b)). In comparison, sizes of the NCCL and RCCL micelles slightly increased, presumably owing to the swelling of micelle cores. These results confirmed the stability of CCL micelles in organic solvents due to the core cross-linking via covalent bonding. Additionally, the stability of the micelles in different media was evaluated over storage for one week. CCL micelles maintained constant
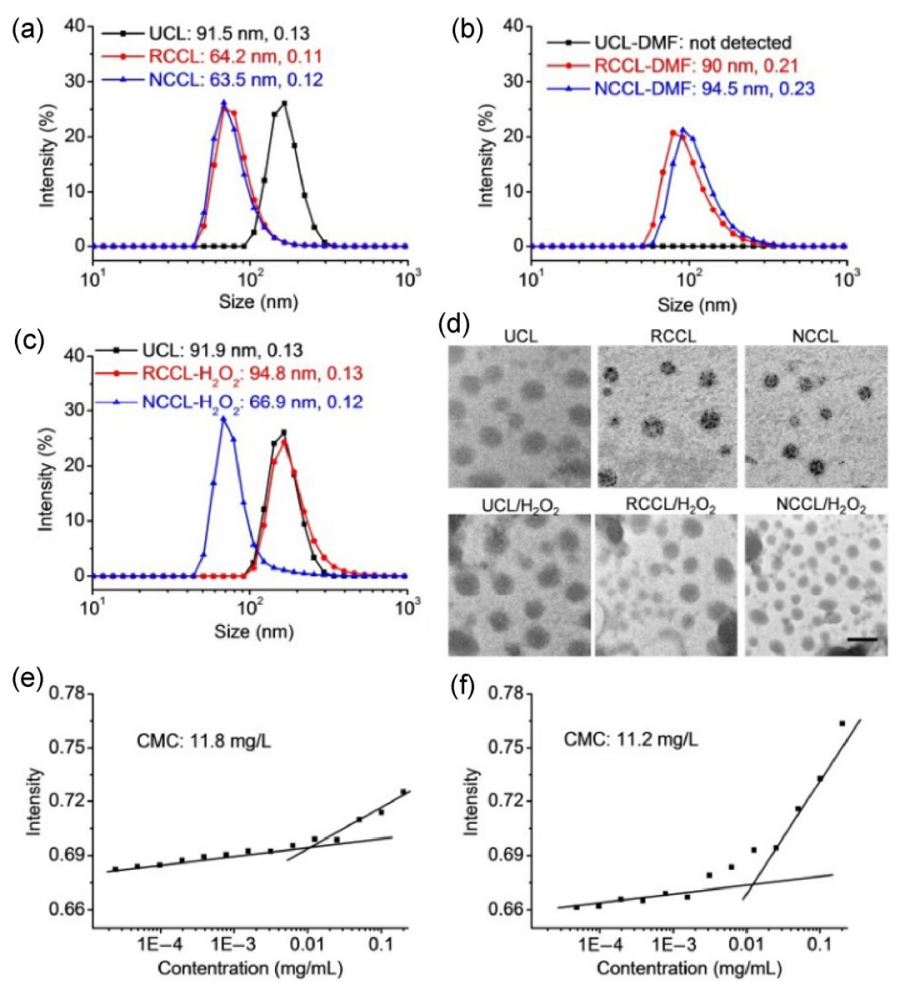

Figure 1 Stability and ROS responsiveness of RCCL micelles. Size of micelles in water (a), after dilution with DMF for 10 fold (b), and after treatment with $0.5 \mathrm{mM} \mathrm{H}_{2} \mathrm{O}_{2}$ (c). (d) TEM images of the micelles before and after $\mathrm{H}_{2} \mathrm{O}_{2}$ treatment $(0.5 \mathrm{mM})$. CMC values of untreated UCL micelles (e) and RCCL micelles treated with $0.5 \mathrm{mM} \mathrm{H}_{2} \mathrm{O}_{2}$ (f). diameters in water $\left(\mathrm{H}_{2} \mathrm{O}\right)$, $\mathrm{PBS}$, cell growth medium (1640 medium), and 10\% FBS (Fig. S6 in the ESM). However, UCL micelles lacking a stable core-cross-linked structure showed significantly increased diameters that indicated aggregation (Fig. S6 in the ESM). After treatment with $\mathrm{H}_{2} \mathrm{O}_{2}$, the diameter of RCCL micelles increased to $\sim 94 \mathrm{~nm}$ (Figs. 1(c) and 1(d)), indicating cleavage of the TK linker and loosening of the micelle core. As a control, NCCL and UCL micelles with no $\mathrm{H}_{2} \mathrm{O}_{2}$ responsiveness maintained constant diameters and unaltered morphologies (Figs. 1(c) and 1(d)). Furthermore, the similar CMC values of UCL micelles $(11.8 \mu \mathrm{g} / \mathrm{mL})$ and $\mathrm{H}_{2} \mathrm{O}_{2}$-treated RCCL micelles $(11.2 \mu \mathrm{g} / \mathrm{mL})$ confirmed the cleavage of TK linkers and de-cross-linking of the RCCL micelles (Figs. 1(e) and 1(f)).

\subsection{Drug loading and in vitro release}

PEG-PBYP polymers could self-assemble into micelles and encapsulate Dox and Ce6 in the cores via hydrophobic interactions. Drug-loaded UCL micelles (UCL-DC) showed large diameter of $171.2 \mathrm{~nm}$ with a wide distribution (Fig. 2(a)). In comparison, the cross-linked RCCL-DC micelles possessed notably smaller diameter of $84.5 \mathrm{~nm}$, as confirmed by DLS analysis and TEM observation (Figs. 2(a) and 2(b)). DLC of Dox and Ce6 in the UCL-DC micelles was relatively low (4.1\% and $0.9 \%$ for Dox and Ce6, respectively), while remarkably higher DLC was noted for the CCL micelles (12\% and $4 \%-5 \%$ for Dox and Ce6, respectively), 3-5 fold higher than the ULC micelles (Table 2). It therefore demonstrated that the core cross-linking would benefit the drug encapsulation due to formation of a more compact hydrophobic core. When both Dox and Ce6 were encapsulated in the micelles, the DLE was slightly lower than that for the single drug-loaded micelles (Table 2). This may be due to the electrostatic repulsion between the polymer backbones and the Ce6 molecules that impeded successful encapsulation into the hydrophobic core.

The drug release from micelles was explored to verify the stability and responsiveness of the RCCL micelles both in the absence and presence of $\mathrm{H}_{2} \mathrm{O}_{2}(0.1$ and $0.5 \mathrm{mM})$, a representative category of ROS. The RCCL-Dox micelles exhibited an $\mathrm{H}_{2} \mathrm{O}_{2}$ concentrationdependent drug release profile. In the absence of $\mathrm{H}_{2} \mathrm{O}_{2}$, the drug release from the RCCL-Dox micelles was quite slow with the cumulative release amount of $\sim 30 \%$ within $36 \mathrm{~h}$. In the presence of
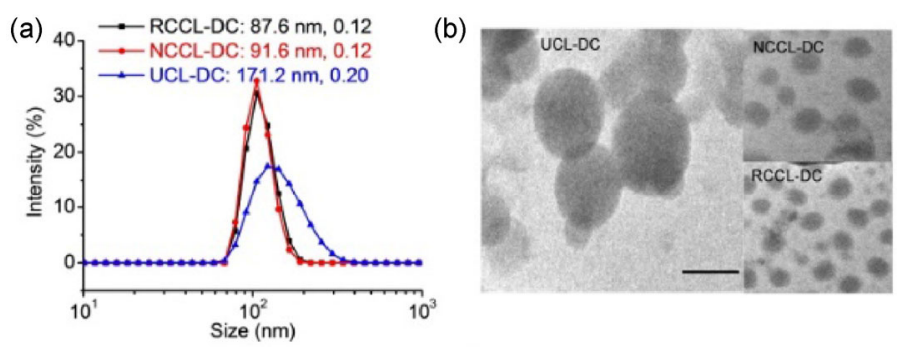

1. NCCL-Dox $\mathrm{H}_{2} \mathrm{O}_{2}(0.5 \mathrm{mM})$ 2. RCCL-Dox $\mathrm{H}_{2} \mathrm{O}_{2}(0 \mathrm{mM})$ 3. RCCL-Dox $\mathrm{H}_{2} \mathrm{O}_{2}(0.1 \mathrm{mM}) 4$. RCCL-Dox $\mathrm{H}_{2} \mathrm{O}_{2}(0.5 \mathrm{mM})$
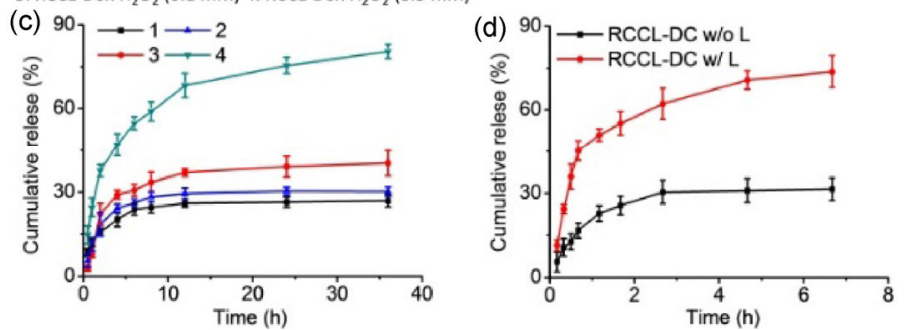

Figure 2 Drug loading and release from the micelles. (a) The size distribution of UCL-DC, RCCL-DC, and NCCL-DC micelles as measured by DLS. (b) Representative TEM images of the drug-loaded micelles. (c) Cumulative Dox release from NCCL-Dox and RCCL-Dox micelles in the presence and absence of $\mathrm{H}_{2} \mathrm{O}_{2}(n=3)$. (d) Cumulative Dox release from RCCL-DC micelles with or without 0.5 -h light irradiation $\left(660 \mathrm{~nm}, 5 \mathrm{~mW} / \mathrm{cm}^{2}\right)(n=3)$. 
Table 1 Abbreviations of micelles

\begin{tabular}{cc}
\hline Abbreviation & Full name \\
\hline UCL & Un-cross-linked micelles \\
CCL & Core-cross-linked micelles \\
RCCL & ROS-responsive core-cross-linked micelles \\
NCCL & Non-responsive core-cross-linked micelles \\
RCCL-Dox & Dox-loaded RCCL micelles \\
RCCL-Ce6 & Ce6-loaded RCCL micelles \\
RCCL-DC & Dox- and Ce6-co-loaded RCCL micelles \\
RCCL-DiR & DiR-loaded RCCL micelles \\
UCL-DC & Dox- and Ce6-co-loaded UCL micelles \\
UCL-DiR & DiR-loaded UCL micelles \\
NCCL-Dox & Dox-loaded NCCL micelles \\
NCCL-Ce6 & Ce6-loaded UCCL micelles \\
NCCL-DC & Dox- and Ce6-co-loaded NCCL micelles \\
\hline
\end{tabular}

Table 2 Characterization of drug-loaded micelles

\begin{tabular}{ccccc}
\hline \multirow{2}{*}{ Micelle } & \multicolumn{2}{c}{ Dox } & \multicolumn{2}{c}{ Ce6 } \\
\cline { 2 - 5 } & DLE (\%) & DLC (\%) & DLE (\%) & DLC (\%) \\
\hline RCCL-Dox & 89.6 & 15.2 & - & - \\
RCCL-Ce6 & - & - & 32.5 & 6.1 \\
RCCL-DC & 84.9 & 12.4 & 30.5 & 4.9 \\
NCCL-DC & 84.2 & 12.3 & 25.6 & 4.0 \\
UCL-DC & 14.3 & 4.1 & 3.3 & 0.9 \\
\hline
\end{tabular}

$0.1 \mathrm{mM} \mathrm{H}_{2} \mathrm{O}_{2}$ (intracellular concentration in cancer cells) [24], drug release was slightly accelerated, indicating that the intracellular ROS was unable to efficiently trigger the de-crosslinking of micelles and drug release (Fig. 2(c)). Comparatively, at elevated $\mathrm{H}_{2} \mathrm{O}_{2}$ concentration $(0.5 \mathrm{mM})$, pronounced drug release was noted, conferring a cumulative release amount of $80 \%$ within $36 \mathrm{~h}$. As a non-responsive analogue, NCCL-Dox micelles showed unaltered release profile in the presence of $0.5 \mathrm{mM} \mathrm{H}_{2} \mathrm{O}_{2}$. Such observation therefore suggested the feasibility to enhance ROS concentration in cancer cells using PDT and accordingly accelerate drug release in response to ROS. In support of such hypothesis, more than $80 \%$ of the loaded Dox was released from RCCL-DC micelles within $4 \mathrm{~h}$ after light irradiation (Fig. 2(d)), indicating that the loaded PS can efficiently produce ROS to break down the TK cross-linker and promote micelle destabilization. Taken together, the introduction of TK cross-linker could not only increase the stability and the drug loading of the micelles, but also provide the micelles with the possibility of on-demand and instantaneous drug release upon external light triggers.

\subsection{Intracellular ROS production}

The light-induced ROS production in 4T1 cells was probed using a ROS probe, DCFH-DA. The non-fluorescent DCFH-DA can be oxidized to fluorescent dichlorofluorescein (DCF) by cellular ROS. After 0.5-h light irradiation $\left(660 \mathrm{~nm}, 5 \mathrm{~mW} / \mathrm{cm}^{2}\right)$, the DCF fluorescence (green) in cells treated with RCCL-Ce6 micelles enhanced significantly, demonstrating sufficient ROS production. However, cells treated with PBS or RCCL-Ce6 micelles without light activation exhibited weak fluorescence signal (Fig. S7 in the ESM). Addition of $\mathrm{Vc}$, an antioxidant to deplete ROS, to the cells before light irradiation could remarkably attenuate the DCF fluorescence intensity in the cells. The results substantiated the enhanced intracellular ROS level induced by light activation of Ce6.

\subsection{In vitro cellular uptake}

The cellular uptake and intracellular distribution of micelles were evaluated in $4 \mathrm{~T} 1$ cells by CLSM and flow cytometry. As shown in
Fig. 3(a), more red fluorescence signal was detected in the cells treated with UCL-Dox micelles than those treated with RCCL-Dox or NCCL-Dox micelles for either 8 or $12 \mathrm{~h}$ (Figs. 3(a) and 3(b)). The same trend was observed for the flow cytometry analysis and the quantified fluorescence intensity (Figs. 3(e)-3(g)). Such discrepancy was probably because UCL-Dox micelles released Dox faster than the CCL micelles, and the fluorescence of the encapsulated Dox in the micelles core could be partially quenched [48]. Nevertheless, when light irradiation $\left(606 \mathrm{~nm}, 5 \mathrm{~mW} / \mathrm{cm}^{2}, 0.5 \mathrm{~h}\right.$ ) was performed at $8 \mathrm{~h}$ post incubation with micelles followed by incubation for another $4 \mathrm{~h}$, the RCCL-DC micelles exhibited comparable intracellular fluorescence intensity to the UCL micelles, notably outperforming the NCCL-DC micelles (Figs. 3(c), 3(h), and 3(i)), These results thus suggested the efficient drug release from RCCL-DC micelles upon light-induced ROS generation.

\subsection{In vitro anti-cancer efficacy}

The cytotoxicity of the blank micelles was first investigated using the MTT assay. The viability of both $4 \mathrm{~T} 1$ and MCF-7 cells remained above $90 \%$ after incubation with micelles at the concentration range from 1 to $500 \mu \mathrm{g} / \mathrm{mL}$, indicating low toxicity of the drug carrier (Fig. S8 in the ESM). Then the anti-cancer efficacy of the drug-loaded micelles was evaluated using the same cell lines. As shown in Figs. 4(a) and 4(b), RCCL-DC micelles exhibited significantly stronger

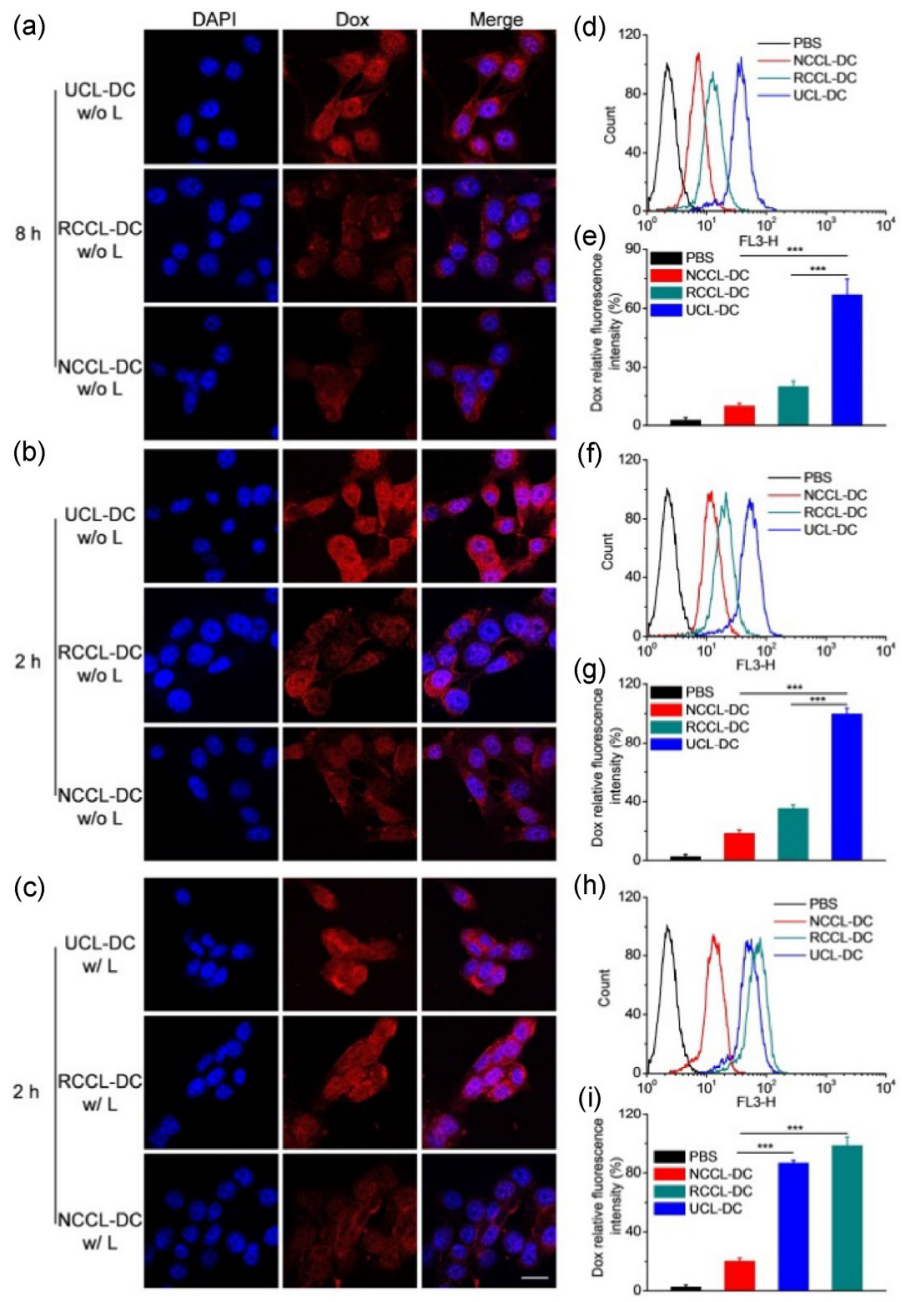

Figure 3 Cellular uptake and intracellular distribution of micelles. (a)-(c) Representative CLSM images of 4T1 cells following incubation with different micelles for 8 or $12 \mathrm{~h}$. Scale bar $=50 \mu \mathrm{m}$. Flow cytometry analysis of the intracellular Dox content after treatment with different micelles for $8 \mathrm{~h} \mathrm{(d)}$ and (e), $12 \mathrm{~h}$ without irradiation (f) and (g), and $12 \mathrm{~h}$ with irradiation (h) and (i). Light irradiation $\left(660 \mathrm{~nm}, 5 \mathrm{~mW} / \mathrm{cm}^{2}, 0.5 \mathrm{~h}\right)$ was performed after 8 -h incubation with micelles $(n=3)$ 
(a)

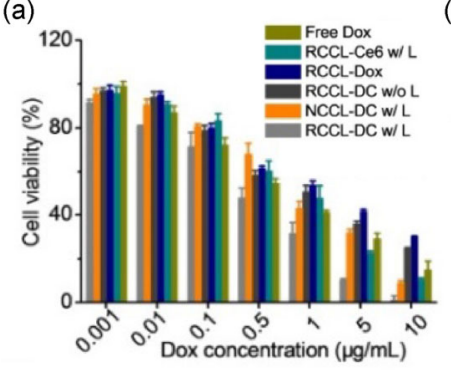

(c)

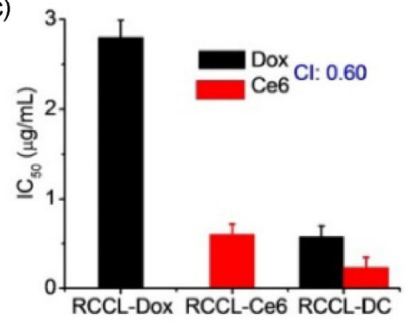

(d)

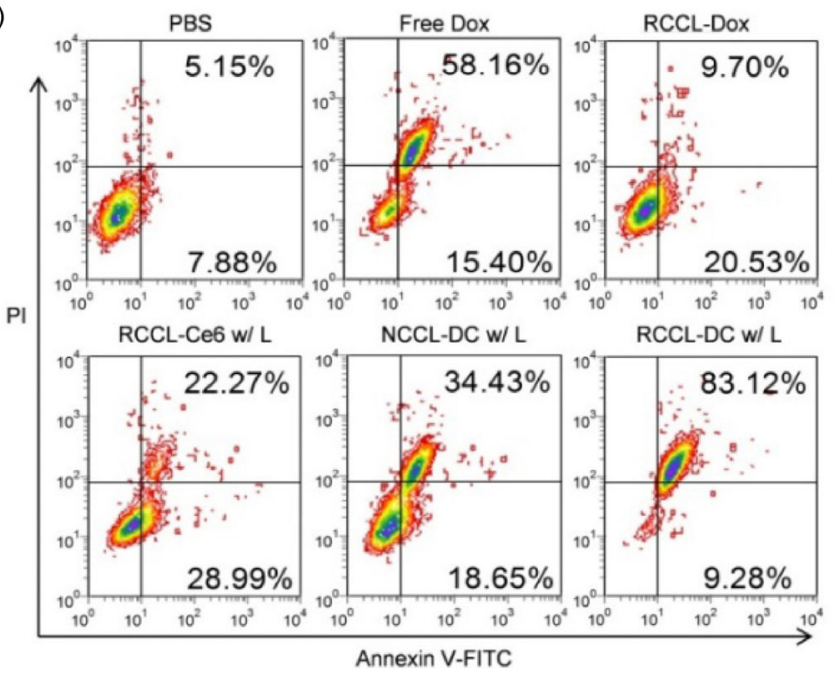

(f)

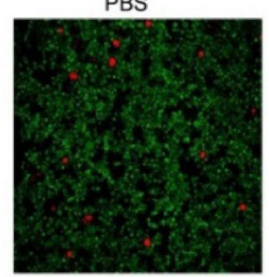

RCCL-Ce6 w/ L

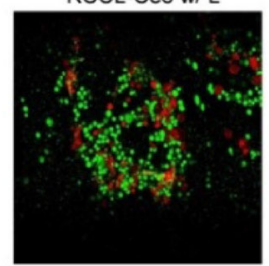

(b)

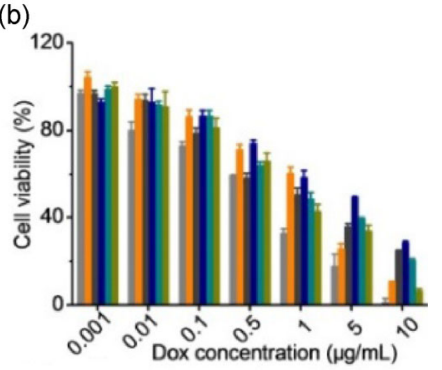

(d)

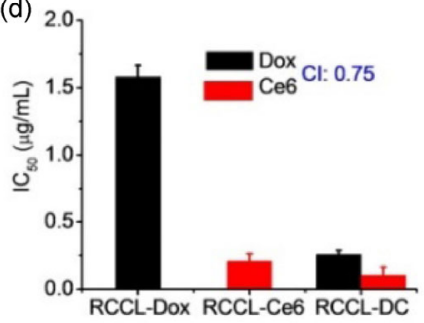

Free Dox

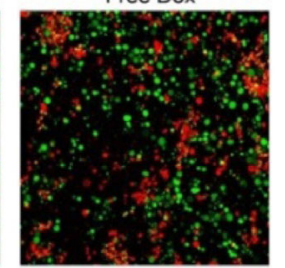

NCCL-DC W/ L

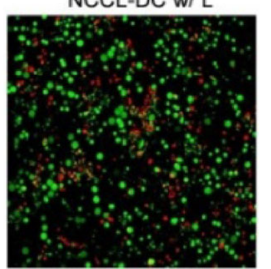

RCCL-Dox



RCCL-DC w/ L

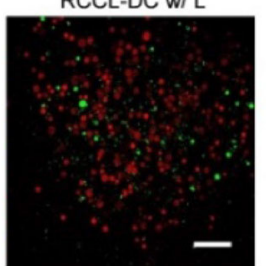

Figure 4 In vitro anti-tumor efficacy of micelles. Viability of 4T1 (a) and MCF-7 (b) cells after treatment with different micelles. IC S0 $_{50}$ Dox and Ce6 in 4T1 (c) and MCF-7 (d) cells after treatment with different micelles. (e) Flow cytometric analysis of 4T1 cells treated with different micelles and stained with Annexin V-FITC/PI. (f) CLSM images of $4 \mathrm{~T} 1$ cells treated with different micelles and double-stained with calcein-AM (green, live cells) and PI (red, dead cells). Scale bar $=100 \mu \mathrm{m}$. For all the experiments, cells were incubated with micelles for $8 \mathrm{~h}$, irradiated $\left(660 \mathrm{~nm}, 5 \mathrm{~mW} / \mathrm{cm}^{2}\right)$ for $0.5 \mathrm{~h}$, and incubated for an additional $48 \mathrm{~h}$ before the assessments.

anticancer efficacy than RCCL-Dox micelles (Dox only), RCCL-Ce6 micelles (Ce6 only), and NCCL-DC micelles (non-responsive) after 30-min light irradiation. The half-maximal inhibitory concentration $\left(\mathrm{IC}_{50}\right)$ of Dox in RCCL-DC micelles $(0.62 \mu \mathrm{g} / \mathrm{mL}$ for $4 \mathrm{~T} 1$ cells

and $0.42 \mu \mathrm{g} / \mathrm{mL}$ for MCF-7 cells) was 3-4-fold lower than that in RCCL-Dox micelles $(2.8 \mu \mathrm{g} / \mathrm{mL}$ for $4 \mathrm{~T} 1$ cells and $1.6 \mu \mathrm{g} / \mathrm{mL}$ for MCF-7 cells). The combination index (CI) between Dox and Ce6 in RCCL-DC micelles was far below 1 ( 0.60 in $4 \mathrm{~T} 1$ cells and 0.75 in MCF-7 cells) (Figs. 4(c) and 4(d)), substantiating the synergistic effect between Dox and Ce6 as a result of the light activated, PS-mediated ROS generation and subsequent ROS-triggered fast Dox release in cancer cells [50].

Additionally, the potency of the drug-loaded micelles to induce cancer cell apoptosis was measured using the Annexin V-FITC/PI assay. As shown in Fig. 4(e), the apoptosis rates induced by RCCLDox, RCCL-Ce6, and NCCL-DC micelles were 30.23\%, 51.26\%, and $53.08 \%$, respectively. In contrast, RCCL-DC micelles induced significantly augmented apoptosis rate of $92.40 \%$, which accorded well with their anti-cancer efficacy as demonstrated by the MTT assay (Fig. 4(a)).

CLSM images were used to visualize both the dead and live cells after treatments, using the calcein-AM and PI double staining assay (Fig. 4(f)). Live cells enzymatically hydrolyze the non-fluorescent calcein-AM to the green fluorescent calcein, while the PI molecule can penetrate the cell membrane of dead cells and bind to DNA to emit red fluorescence [51]. Compared with cells treated with RCCL-Dox, RCCL-Ce6, and NCCL-DC micelles, cells treated with RCCL-DC micelles showed the highest density of red fluorescence, indicating their strongest cancer cell killing efficiency (Fig. 4(f)).

\subsection{Pharmacokinetics and biodistribution}

As shown in Fig. 5(a), RCCL-DiR micelles exhibited prolonged blood circulation time than free $\mathrm{DiR}$ and UCL-DiR micelles after i.v. injection, and the half-life $\left(t_{1 / 2}\right)$ of the RCCL-DiR micelles was $5.3 \mathrm{~h}$, 2.1- and 10.6-fold longer than UCL-DiR micelles $(2.5 \mathrm{~h})$ and free $\operatorname{DiR}(0.5 \mathrm{~h})$, respectively. Such prolonged blood circulation time of RCCL micelles may be attributed to the stealth property of the PEG shells and the stable core-cross-linked structures of the CCL micelles that prevented dissociation and pre-leakage of the drug cargoes upon extensive dilution by the blood. The biodistribution of micelles was further assessed in 4T1 xenograft tumor-bearing mice. As shown in Fig. 5(b), RCCL-DiR micelles showed notably stronger fluorescence (a)

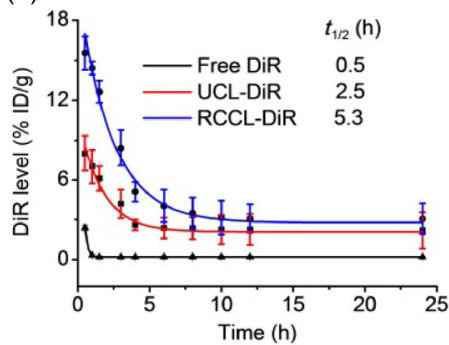

(c)

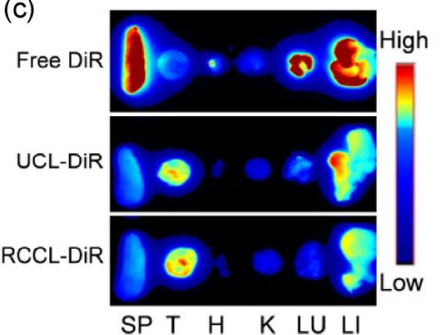

(b)

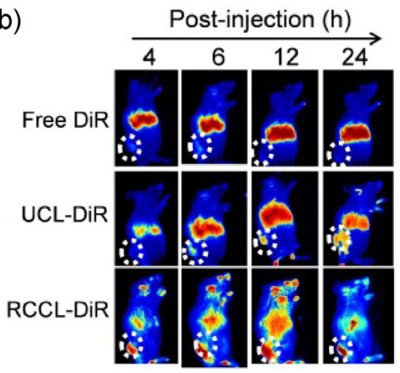

(d)

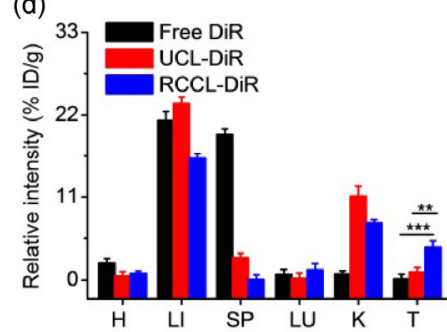

Figure 5 Pharmacokinetics and biodistribution of micelles. (a) Pharmacokinetics of RCCL-DiR micelles, UCL-DiR micelles, and free DiR following i.v. injection $(n=3)$. (b) Fluorescence imaging of $4 \mathrm{~T} 1$ tumor-bearing mice at different time post i.v. injection of RCCL-DiR micelles, UCL-DiR micelles, and free DiR. (c) Ex vivo fluorescence imaging of excised tumors and major organs at $12 \mathrm{~h}$ post i.v. injection (H: heart; LI: liver; SP: spleen; LU: lung; K: kidney; T: tumor). (d) Biodistribution levels of DiR in tumors and major organs at $12 \mathrm{~h}$ post i.v. injection $(n=3)$. 
intensity of DiR in the tumors than free DiR and UCL-DiR micelles, and the fluorescence intensity peaked at $12 \mathrm{~h}$ post injection. After injection, most of the free DiR was accumulated and trapped in livers, and UCL-DiR micelles also showed a progressive accumulation in livers owing to the undesired stability of the micelles (Fig. 5(b)). Notably, the RCCL micelles showed pronounced passive targeting to tumor sites mainly ascribed to the prolonged systemic circulation and the EPR effect. Then, the major organs and tumors were harvested at $12 \mathrm{~h}$ post injection, and the ex vivo fluorescence intensity further quantified (Figs. 5(c) and 5(d)). The DiR content in the tumors treated with RCCL-DiR micelles was 8- and 2-fold higher than those of DiR- and UCL-DiR micelles-treated tumors, respectively. Taken together, these findings demonstrated the advantage of the RCCL micelles with chemically-stabilized structure to enable prolonged blood circulation and enhanced tumor accumulation following i.v. injection.

\subsection{In vivo antitumor efficacy}

A 4T1 xenograft tumor-bearing murine model was used to evaluate the anticancer efficacy of the micelles. The mice were i.v. injected with PBS, free Dox (5 mg/kg), RCCL-Dox (10 mg Dox $/ \mathrm{kg}$ ), RCCLCe6 (4 mg Ce6/kg), NCCL-DC (10 mg Dox/kg, $4 \mathrm{mg} \mathrm{Ce6/kg),} \mathrm{and}$ RCCL-DC (10 mg Dox $/ \mathrm{kg}, 4 \mathrm{mg} \mathrm{Ce} 6 / \mathrm{kg}$ ). Free Dox was injected at $5 \mathrm{mg} / \mathrm{kg}$ due to its serious heart toxicity [50]. Based on the biodistribution results, 30-min light irradiation was applied at $12 \mathrm{~h}$ post injection. As indicated in Figs. 6(a) and 6(b), the tumors after treatment with PBS grew rapidly and reached the size around $1,200 \mathrm{~mm}^{3}$ within 16 days. Free Dox and RCCL-Dox showed similar and weak tumor inhibition efficacy. RCCL-Ce6 and NCCL-DC

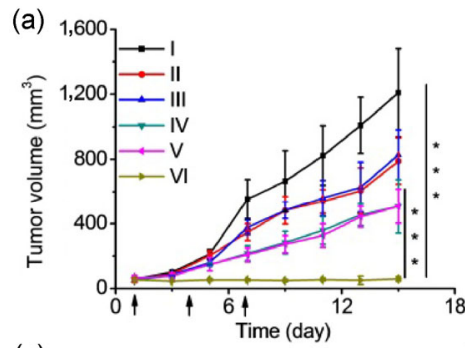

(c)
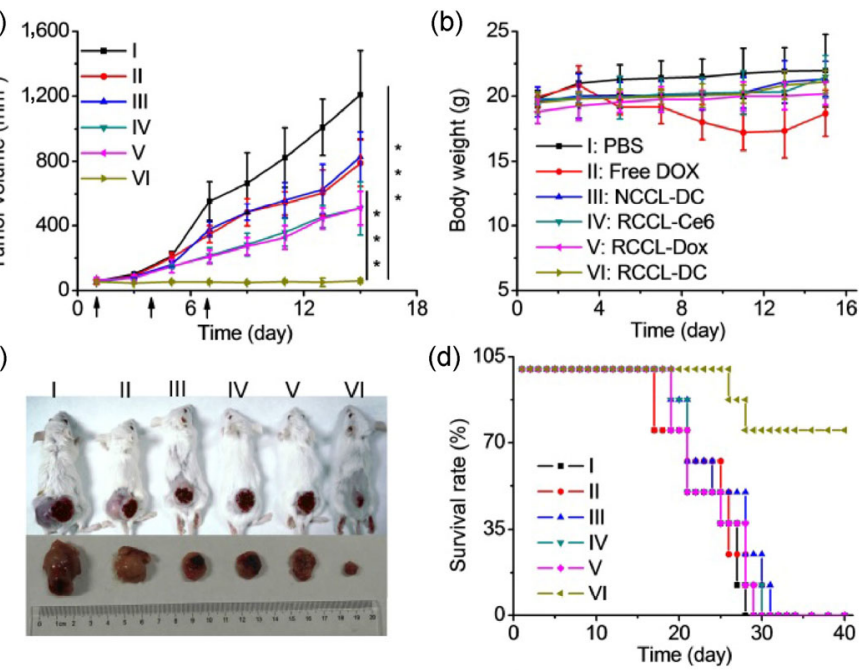

(e)

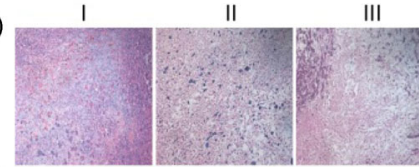

IV

$\mathrm{V}$ VI

(f)

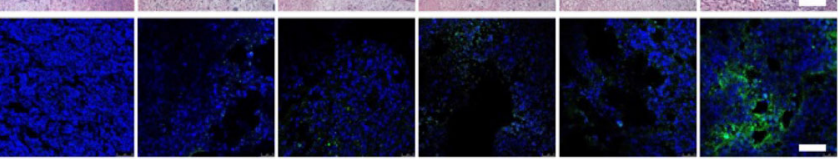

Figure 6 Anti-tumor efficacy of drug-loaded micelles in 4T1 tumor-bearing mice. Tumor volume (a) and body weight (b) of mice during the 16-day observation period. (c) Representative images of tumors on day 16 (b). (d) Survival rate of mice within the 40-day observation period. (e) H\&E-stained tumor tissues on day 16. Scale bar $=100 \mu \mathrm{m}$. (f) Cell apoptosis in tumor tissues harvested on day 16 as determined by TUNEL staining. Scale bar $=100 \mu \mathrm{m}$. Mice were i.v. injected with PBS, free Dox, RCCL-Dox micelles, RCCL-Ce6 micelles, NCC-DC micelles, and RCCL-DC micelles on day 1, 4 and 7 (4 mg Ce6/ $\mathrm{kg}$ and $10 \mathrm{mg}$ Dox, $/ \mathrm{kg}$ for micelles, $5 \mathrm{mg} / \mathrm{kg}$ for free Dox $)(n=8)$. Tumor sites were irradiated $\left(660 \mathrm{~nm}, 5 \mathrm{~mW} / \mathrm{cm}^{2}\right)$ for $0.5 \mathrm{~h}$ at $12 \mathrm{~h}$ post injection of micelles. micelles showed a stronger inhibition rate of tumor growth compared to free Dox, which could be due to the photodynamic effect of the encapsulated Ce6. Importantly, the RCCL-DC micelles, upon light activation, completely suppressed the growth of solid tumors within the 16-day observation period. Among all the treatments, free Dox showed remarkable side effect as evidenced by a $\sim 10 \%$ reduction of the body weight (Fig. 6(c)), while negligible body weight loss was noted for all test micelles. In accordance with the tumor inhibition capability, the RCCL-DC micelles significantly enhanced the survival rate of the tumor-bearing mice over the 40-day observation period (Fig. 6(d)). Additionally, tumors treated with RCCL-DC micelles exhibited the highest tumor cell remission rate in $\mathrm{H} \& \mathrm{E}$-stained tumor tissues (Fig. 6(e)) and the highest tumor cell apoptosis rate after TUNEL staining (Fig. 6(f)). Histological observation on major organs revealed lack of pathological abnormalities following treatment with RCCL-DC micelles (Fig. S9 in the ESM). These results collectively demonstrated the effective and synergistic anti-cancer effect of the RCCL micelles, which would undergo ROS-induced destabilization upon light irradiation to accelerate Dox release and thereby enabling potent and synergistic anti-cancer efficacy with negligible side toxicity to normal tissues.

\section{Conclusions}

In summary, we developed a ROS-responsive CCL micellar system to enhance the circulation stability and allow on-demand chemodrug release via PS-induced ROS generation upon far red light irradiation. The RCCL micelles were core-cross-linked via a TK-containing linker, which efficiently stabilized the micelles, enhanced the loading capacity for Dox and Ce6, and prevented the pre-leakage of drug cargoes upon dilution. In the tumor tissues, the loaded Ce6 in RCCL-DC micelles produced extensive ROS under light activation to cleave the TK linkers and disrupt the micelle cores. As such, micelles were destabilized to accelerate Dox release, thereby provoking synergistic anti-cancer effect with ROS-mediated photodynamic therapy. This study provides an effective strategy to resolve the dilemma of formulation stability and effective as well as cancerselective drug release, and would thus render a promising modality for the anti-cancer combination therapy.

\section{Acknowledgements}

This work was supported by the National Natural Science Foundation of China (Nos. 51722305, 51573123, and 51873142), the Ministry of Science and Technology of China (No. 2016YFA0201200), the 111 Project, and Priority Academic Program Development of Jiangsu Higher Education Institutions (PAPD).

Electronic Supplementary Material: Supplementary material (the synthetic routes of PEG-PBYP, ${ }^{1} \mathrm{H}$ NMR spectra, size variations of micelles, cytotoxicity, tissue histology, etc.) is available in the online version of this article at https://doi.org/10.1007/s12274-019-2330-y.

Open Access: This article is licensed under a Creative Commons Attribution 4.0 International License, which permits use, sharing, adaptation, distribution and reproduction in any medium or format, as long as you give appropriate credit to the original author(s) and the source, provide a link to the Creative Commons licence, and indicate if changes were made.

The images or other third party material in this article are included in the article's Creative Commons licence, unless indicated otherwise in a credit line to the material. If material is not included in the article's Creative Commons licence and your intended use is not permitted by statutory regulation or exceeds the permitted use, you will need to obtain permission directly from the copyright holder. 
To view a copy of this licence, visit http://creativecommons.org/ licenses/by/4.0/.

\section{References}

[1] Wicki, A.; Witzigmann, D.; Balasubramanian, V.; Huwyler, J. Nanomedicine in cancer therapy: Challenges, opportunities, and clinical applications. J. Control. Release 2015, 200, 138-157.

[2] Kwon, G. S.; Okano, T. Polymeric micelles as new drug carriers. $A d v$. Drug Deliv. Rev. 1996, 21, 107-116.

[3] Kataoka, K.; Harada, A.; Nagasaki, Y. Block copolymer micelles for drug delivery: Design, characterization and biological significance. Adv. Drug Deliv. Rev. 2012, 64, 37-48.

[4] Duncan, R. The dawning era of polymer therapeutics. Nat. Rev. Drug Dis. 2003, 2, 347-360.

[5] Aouameur, D.; Cheng, H.; Opoku-Damoah, Y.; Sun, B.; Dong, Q. L.; Han, Y.; Zhou, J. P.; Ding, Y. Stimuli-responsive gel-micelles with flexible modulation of drug release for maximized antitumor efficacy. Nano Res. 2018, 11, 4245-4264.

[6] Stuart, M. A. C.; Huck, W. T. S.; Genzer, J.; Müller, M.; Ober, C.; Stamm, M.; Sukhorukov, G. B.; Szleifer, I.; Tsukruk, V. V.; Urban, M. et al. Emerging applications of stimuli-responsive polymer materials. Nat. Mater. 2010, 9 , 101-113.

[7] Cao, Z. Y.; Ma, Y. C.; Sun, C. Y.; Lu, Z. D.; Yao, Z. Y.; Wang, J. X.; Li, D. D.; Yuan, Y. Y.; Yang, X. Z. ROS-sensitive polymeric nanocarriers with red light-activated size shrinkage for remotely controlled drug release. Chem. Mater. 2017, 30, 517-525.

[8] Ding, D.; Zhu, Z. S.; Li, R. T.; Li, X. L.; Wu, W.; Jiang, X. Q.; Liu, B. R. Nanospheres-incorporated implantable hydrogel as a trans-tissue drug delivery system. ACS Nano 2011, 5, 2520-2534.

[9] Phelps, E. A.; Enemchukwu, N. O.; Fiore, V. F.; Sy, J. C.; Murthy, N.; Sulchek, T. A.; Barker, T. H.; García, A. J. Maleimide cross-linked bioactive peg hydrogel exhibits improved reaction kinetics and cross-linking for cell encapsulation and in situ delivery. Adv. Mater. 2012, 24, 64-70.

[10] Wang, P.; Wang, J. X.; Tan, H. W.; Weng, S. F.; Cheng, L. Y.; Zhou, Z. P.; Wen, S. Acid- and reduction-sensitive micelles for improving the drug delivery efficacy for pancreatic cancer therapy. Biomater. Sci. 2018, 6, $1262-1270$.

[11] Shuai, X. T.; Merdan, T.; Schaper, A. K.; Xi, F.; Kissel, T. Core-cross-linked polymeric micelles as paclitaxel carriers. Bioconjugate Chem. 2004, 15, 441-448.

[12] Talelli, M.; Barz, M.; Rijcken, C. J. F.; Kiessling, F.; Hennink, W. E.; Lammers, T. Core-crosslinked polymeric micelles: Principles, preparation, biomedical applications and clinical translation. Nano Today 2015, 10, 93-117.

[13] Li, Y. P.; Xiao, K.; Luo, J. T.; Xiao, W. W.; Lee, J. S.; Gonik, A. M.; Kato, J.; Dong, T. A.; Lam, K. S. Well-defined, reversible disulfide cross-linked micelles for on-demand paclitaxel delivery. Biomaterials 2011, 32, $6633-6645$.

[14] Gulfam, M.; Matini, T.; Monteiro, P. F.; Riva, R.; Collins, H.; Spriggs, K.; Howdle, S. M.; Jérôme, C.; Alexander, C. Bioreducible cross-linked core polymer micelles enhance in vitro activity of methotrexate in breast cancer cells. Biomater. Sci. 2017, 5, 532-550.

[15] Pitarresi, G.; Casadei, M. A.; Mandracchia, D.; Paolicelli, P.; Palumbo, F. S.; Giammona, G. Photocrosslinking of dextran and polyaspartamide derivatives: A combination suitable for colon-specific drug delivery. $J$. Control. Release 2007, 119, 328-338.

[16] Ding, J. X.; Zhuang, X. L.; Xiao, C. S.; Cheng, Y. L.; Zhao, L.; He, C. L.; Tang, Z. H.; Chen, X. S. Preparation of photo-cross-linked pH-responsive polypeptide nanogels as potential carriers for controlled drug delivery. $J$. Mater. Chem. 2011, 21, 11383-11391.

[17] Yang, S. C.; Tang, Z. H.; Zhang, D. W.; Deng, M. X.; Chen, X. S. pH and redox dual-sensitive polysaccharide nanoparticles for the efficient delivery of doxorubicin. Biomater. Sci. 2017, 5, 2169-2178.

[18] Li, J. M.; Liu, Y.; Li, H. L.; Shi, W.; Bi, X. Z.; Qiu, Q. Q.; Zhang, B.; Huang, W. L.; Qian, H. pH-sensitive micelles with mitochondria-targeted and aggregation-induced emission characterization: Synthesis, cytotoxicity and biological applications. Biomater. Sci. 2018, 6, 2998-3008.

[19] Li, X.; Li, H.; Yi, W.; Chen, J. Y.; Liang, B. L. Acid-triggered core crosslinked nanomicelles for targeted drug delivery and magnetic resonance imaging in liver cancer cells. Int. J. Nanomedicine 2013, 8, 3019-3031.

[20] Wang, X. R.; Liu, G. H.; Hu, J. M.; Zhang, G. Y.; Liu, S. Y. Concurrent block copolymer polymersome stabilization and bilayer permeabilization by stimuli-regulated "traceless" crosslinking. Angew. Chem. 2014, 126, 3202-3206.

[21] Zhang, Z. H.; Yin, L. C.; Tu, C. L.; Song, Z. Y.; Zhang, Y. F.; Xu, Y. X.; Tong, R.; Zhou, Q.; Ren, J.; Cheng, J. J. Redox-responsive, core cross-linked polyester micelles. ACS Macro Lett. 2013, 2, 40-44.

[22] Zhang, Y.; Guo, Q.; An, S.; Lu, Y. F.; Li, J. F.; He, X.; Liu, L. S.; Zhang, Y. J.; Sun, T.; Jiang, C. ROS-switchable polymeric nanoplatform with stimuliresponsive release for active targeted drug delivery to breast cancer. ACS Appl. Mater. Interfaces 2017, 9, 12227-12240.

[23] Hu, X. L.; Chen, X. S.; Wei, J. Z.; Liu, S.; Jing, X. B. Core crosslinking of biodegradable block copolymer micelles based on poly(ester carbonate). Macromol. Biosci. 2009, 9, 456-463.

[24] Li, J.; Sun, C. Y.; Tao, W.; Cao, Z. Y.; Qian, H. S.; Yang, X. Z.; Wang, J. Photoinduced PEG deshielding from ROS-sensitive linkage-bridged block copolymer-based nanocarriers for on-demand drug delivery. Biomaterials 2018, 170, 147-155.

[25] Ruan, C. H.; Liu, L. S.; Wang, Q. B.; Chen, X. L.; Chen, Q. J.; Lu, Y. F.; Zhang, Y.; He, X.; Zhang, Y. J.; Guo, Q. et al. Reactive oxygen speciesbiodegradable gene carrier for the targeting therapy of breast cancer. ACS Appl. Mater. Interfaces 2018, 10, 10398-10408.

[26] Kramer, J. R.; Deming, T. J. Glycopolypeptides with a redox-triggered helix-to-coil transition. J. Am. Chem. Soc. 2012, 134, 4112-4115.

[27] Han, P.; Li, S. C.; Cao, W.; Li, Y.; Sun, Z. W.; Wang, Z. Q.; Xu, H. P. Red light responsive diselenide-containing block copolymer micelles. J. Mater. Chem. B 2013, 1, 740-743.

[28] Liu, J. Y.; Pang, Y.; Zhu, Z. Y.; Wang, D. L.; Li, C. T.; Huang, W.; Zhu, X. Y.; Yan, D. Y. Therapeutic nanocarriers with hydrogen peroxide-triggered drug release for cancer treatment. Biomacromolecules 2013, 14, 1627-1636.

[29] Wang, L.; Fan, F. Q.; Cao, W.; Xu, H. P. Ultrasensitive ROS-responsive coassemblies of tellurium-containing molecules and phospholipids. ACS Appl. Mater. Interfaces 2015, 7, 16054-16060.

[30] Cao, W.; Gu, Y. W.; Li, T. Y.; Xu, H. P. Ultra-sensitive ROS-responsive tellurium-containing polymers. Chem. Commun. 2015, 51, 7069-7071.

[31] Wang, J. Q.; Zhang, Y. Q.; Archibong, E.; Ligler, F. S.; Gu, Z. Leveraging $\mathrm{H}_{2} \mathrm{O}_{2}$ levels for biomedical applications. Adv. Biosyst. 2017, 1, 1700084.

[32] Wang, C.; Wang, J. Q.; Zhang, X. D.; Yu, S. J.; Wen, D.; Hu, Q. Y.; Ye, Y. Q.; Bomba, H.; Hu, X. L.; Liu, Z. et al. In situ formed reactive oxygen species-responsive scaffold with gemcitabine and checkpoint inhibitor for combination therapy. Sci. Transl. Med. 2018, 10, eaan3682.

[33] Song, X. J.; Feng, L. Z.; Liang, C.; Gao, M.; Song, G. S.; Liu, Z. Liposomes co-loaded with metformin and chlorin e6 modulate tumor hypoxia during enhanced photodynamic therapy. Nano Res. 2017, 10, 1200-1212.

[34] Bhaumik, J.; Mittal, A. K.; Banerjee, J.; Chisti, Y.; Banerjee, U. C. Applications of phototheranostic nanoagents in photodynamic therapy. Nano Res. 2015, 8, 1373-1394.

[35] Dang, J. J.; He, H.; Chen, D. L.; Yin, L. C. Manipulating tumor hypoxia toward enhanced photodynamic therapy (PDT). Biomater. Sci. 2017, 5, $1500-1511$.

[36] Dolmans, D. E. J. G. J.; Fukumura, D.; Jain, R. K. Photodynamic therapy for cancer. Nat. Rev. Cancer 2003, 3, 380-387.

[37] Sung, S. Y.; Su, Y. L.; Cheng, W.; Hu, P. F.; Chiang, C. S.; Chen, W. T.; Hu, S. H. Graphene quantum dots-mediated theranostic penetrative delivery of drug and photolytics in deep tumors by targeted biomimetic nanosponges. Nano Lett. 2018, 19, 69-81.

[38] Cui, S. S.; Yin, D. Y.; Chen, Y. Q.; Di, Y. F.; Chen, H. Y.; Ma, Y. X.; Achilefu, S.; Gu, Y. Q. In vivo targeted deep-tissue photodynamic therapy based on near-infrared light triggered upconversion nanoconstruct. ACS Nano 2013, 7, 676-688.

[39] Idris, N. M.; Gnanasammandhan, M. K.; Zhang, J.; Ho, P. C.; Mahendran, R.; Zhang, Y. In vivo photodynamic therapy using upconversion nanoparticles as remote-controlled nanotransducers. Nat. Med. 2012, 18, 1580-1585. 
[40] Qin, W.; Ding, D.; Liu, J. Z.; Yuan, W. Z.; Hu, Y.; Liu, B.; Tang, B. Z. Biocompatible nanoparticles with aggregation-induced emission characteristics as far-red/near-infrared fluorescent bioprobes for in vitro and in vivo imaging applications. Adv. Funct. Mater. 2012, 22, 771-779.

[41] Du, X. Q.; Sun, Y.; Zhang, M. Z.; He, J. L.; Ni, P. H. Polyphosphoestercamptothecin prodrug with reduction-response prepared via michael addition polymerization and click reaction. ACS Appl. Mater. Interfaces 2017, 9 , 13939-13949.

[42] Hu, J.; He, J. L.; Zhang, M. Z.; Ni, P. H. Folate-conjugated biodegradable core cross-linked polyphosphoester micelles for targeted and $\mathrm{pH}$-triggered drug delivery. J. Control. Release 2015, 213, e86-e87.

[43] Yuan, Y. Y.; Liu, J.; Liu, B. Conjugated-polyelectrolyte-based polyprodrug: Targeted and image-guided photodynamic and chemotherapy with ondemand drug release upon irradiation with a single light source. Angew. Chem. 2014, 126, 7291-7296.

[44] Mock, W. L.; Irra, T. A.; Wepsiec, J. P.; Manimaran, T. L. Cycloaddition induced by cucurbituril. A case of Pauling principle catalysis. J. Org. Chem. 1983, 48, 3619-3620.

[45] He, Y. Y.; Cheng, G.; Xie, L.; Nie, Y.; He, B.; Gu, Z. W. Polyethyleneimine/ DNA polyplexes with reduction-sensitive hyaluronic acid derivatives shielding for targeted gene delivery. Biomaterials 2013, 34, 1235-1245.
[46] Li, F. F.; Li, Y. J.; Zhou, Z. C.; Lv, S. X.; Deng, Q. R.; Xu, X.; Yin, L. C. Engineering the aromaticity of cationic helical polypeptides toward "self-activated" DNA/siRNA delivery. ACS Appl. Mater. Interfaces 2017, 9, 23586-23601.

[47] Lv, S. X.; Wu, Y. C.; Dang, J. Q.; Tang, Z. H.; Song, Z. Y.; Ma, S.; Wang, X.; Chen, X S.; Cheng, J. J.; Yin, L. C. Investigation on the controlled synthesis and post-modification of poly-[(N-2-hydroxyethyl)-aspartamide]based polymers. Polym. Chem. 2017, 8, 1872-1877.

[48] Deepagan, V. G.; Kwon, S.; You, D. G.; Van Quy Nguyen; Um, W.; Ko, H.; Lee, H.; Jo, D. G.; Kang, Y. M.; Park, J. H. In situ diselenide-crosslinked polymeric micelles for ROS-mediated anticancer drug delivery. Biomaterials 2016, 103, 56-66.

[49] Zhao, Z.; Wang, J.; Mao, H. Q.; Leong, K. W. Polyphosphoesters in drug and gene delivery. Adv. Drug Deliv. Rev. 2003, 55, 483-499.

[50] Li, Y. J.; Lv, S. X.; Song, Z. Y.; Dang, J. J.; Li, X. D.; He, H.; Xu, X.; Zhou, Z. C.; Yin, L. C. Photodynamic therapy-mediated remote control of chemotherapy toward synergistic anticancer treatment. Nanoscale 2018, $10,14554-14562$

[51] Liu, Y.; Song, N.; Chen, L.; Xie, Z. G. Bodipy@ir(III) complexes assembling organic nanoparticles for enhanced photodynamic therapy. Chin. J. Polym. Sci. 2018, 36, 417-424. 